\title{
Effects of 1-Sar-8-Ile-Angiotensin II on Urinary Prostaglandin Excretion in Patients with Essential Hypertension
}

\author{
Minoru Yasujima, Keishi Abe, Yotchi Otsuka, Satoru \\ Chiba, Kancho Ritsu, Nobuo Irokawa, Masahide Seino, \\ Yutaka Sakurai, Keitaro Satto, Toru Ito and Kaoru \\ Yoshinaga \\ The Second Department of Internal Medicine, Tohoku University \\ School of Medicine, Sendai 980
}

Yasujlua, M., Abe, K., Otsuka, Y., Chiba, S., Ritsu, K., Irokawa, N., Seino, M., Sakurar, Y., Sarto, K., Ito, T. and Yoshinaga, K. Effects of 1-Sar8-Ile-Angiotensin II on Urinary Prostaglandin Excretion in Patients with Essential Hypertension. Tohoku J. exp. Med., 1977, 123 (3), 271-278 - To investigate the interaction between the renin angiotensin aldosterone system and the renal prostaglandin ( $P G)$, urinary excretion of $P G E$, urinary excretion of main urinary metabolite (MUM) of PGF2 $\alpha$, urinary excretion of aldosterone, and plasma renin activity were measured before and after infusion of 1-Sar-8-Ile-Angiotensin II, a specific competitive inhibitor of angiotensin II, in 18 patients with essential hypertension under normal and low sodium diets. The values of urinary sodium excretion in these patients before the infusion of the peptide were $160.8 \pm$ 13.3 and $27.0 \pm 2.7 \mathrm{mEq}$ per day on normal and low sodium diet, respectively. On normal sodium diet, urinary excretion of PGE was found to correlate with the level of plasma renin activity before the infusion $(r=0.6977, p<0.01)$, and it was decreased slightly from $0.37 \pm 0.05 \mathrm{ng} / \mathrm{min}$ to $0.26 \pm 0.04 \mathrm{ng} / \mathrm{min}$ after the infusion of the antagonist. On low sodium diet, urinary excretion of PGE was not significantly changed by the infusion of the peptide and showed no correlation with the level of plasma renin activity before the infusion, while urinary excretion of $\mathrm{PGE}$ showed a significant correlation with the excretion of urinary aldosterone $(r=0.6719, p<0.02)$. Excretion of $\mathrm{PGF} 2 \alpha M U M$ decreased after the infusion of this peptide on both sodium diets, but the changes were not statistically significant. The present data suggest that angiotensin II influences the synthesis or release of renal $\mathrm{PG}$ in patients with essential hypertension on normal sodium diet, but not when they are on low sodium diet.___ 1-Sar-8-Ile-Ang II; PRA; aldosterone; PGE; PGF2aMUM

It is well known that the kidney is implicated in the antihypertensive function for which renomedullary $\mathrm{PG}$ might be, at least in part, responsible in human and experimental hypertension (McGiff and Vane 1975; Lee et al. 1976). Recently, an interaction of the renin angiotensin aldosterone system and renal $P G$ has been suggested (Vane and McGiff 1975; Satoh and Zimmerman 1975; Nasjletti and Colina-Chourio 1976). This prompted us to investigate the possibility that the renin angiotensin aldosterone, a renal pressor system, might have an effect on the

Received for publication, April 26, 1977. 
synthesis or release of renal $\mathrm{PG}$ in hypertensive patients. In the present study, the effects of 1-Sar-8-Ile-Angiotensin II, a specific competitive inhibitor of antiotensin II, on urinary excretion of PGE and PGF2aMUM have been investigated in patients with essential hypertension.

\section{Patients and Methods}

Eighteen patients with essential hypertension were included in this study. All patients were studied in Tohoku University Hospital. The diagnosis has been made on the bases of physical and laboratory examinations, intravenous pyelography, plasma renin activity, plasma aldosterone level, urinary catecholamines and vanillylmandelic acid. They consisted of 12 men and 6 women ranging in age from 15 to 53 years with an average of 33. Blood pressures of these patients were $150 \mathrm{mmHg}$ in systolic and $90 \mathrm{mmHg}$ in diastolic or higher on repeated observations. There was no evidence of severe hypertensive complications in cardiovascular and renal organs.

Antihypertensive drugs had been discontinued at least 2 weeks prior to the study. They were allowed to take an unrestricted diet containing approximately $250 \mathrm{mEq}$ of sodium per day for at least 2 weeks before receiving the first infusion of 1-Sar-8-Ile-Antiotensin II. Thereafter, they were brought into a low sodium diet $(50 \mathrm{mEq}$ per day) and on the fourth day they received the second infusion of this peptide.

Sampling of 1 hour's urine was done in the morning from the patients in recumbent position. Then, 1-Sar-8-Mle-Angiotensin II was infused intravenously at 300 and $600 \mathrm{ng} / \mathrm{kg} /$ $\min$ for each $30 \mathrm{~min}$. At the end of 1 hour's infusion, the urine was collected again. Samples of peripheral vein blood were also taken before and at the end of the infusion.

Urinary PGE was measured radioimmunologically. After the chemical conversion of PGE to PGB according to the method described by Zusman (1972), the samples were acidified and extracted with ethyl acetate. Then, the extract was chromatographed as described by Jaffe et al. (1973). PGB equivalents were measured with antisera to PGB available in commercial kits (CA 501, Clinical Assays). Main urinary metabolite of PGF2 $\alpha$ was measured radioimmunologically by Ohki's method (1975). Urinary aldosterone was also determined by radioimmunoassay with commercial kits after being extracted by the procedure described by Langen et al. (1974) and plasma renin activity was determined as described previously (Abe et al. 1972).

\section{Results}

\section{Effect of 1-Sar-8-Ile-Angiotensin II on urinary PGE excretion}

Fig. I demonstrates the changes of urinary PGE excretion following the infusion of 1-Sar-8-Ile-Angiotensin II in the patients on normal and low sodium diets. Decrease in urinary PGE excretion was observed in 17 out of 18 cases on normal sodium intake after the administration of this peptide, namely, from $0.37 \pm$ 0.05 (mean \pm s.E.) to $0.26 \pm 0.04 \mathrm{ng} / \mathrm{min}(p<0.05)$.

On a low sodium diet, urinary PGE excretion after the infusion of the peptide decreased in 11 cases but increased in the remaining 7 cases. The average PGE excretions before and after the infusion of the peptide were $0.25 \pm 0.03$ and $0.22 \pm$ $0.03 \mathrm{ng} / \mathrm{min}$, respectively. The changes were not significant.

\section{Effect of 1-Sar-8-Ile-Angiotensin II on PGF2aMUM excretion}

A slight decrease in PGF2 aMUM excretion was observed in 17 out of 18 cases on normal sodium intake after the administration of 1-Sar-8-Ile-Angiotensin II. 


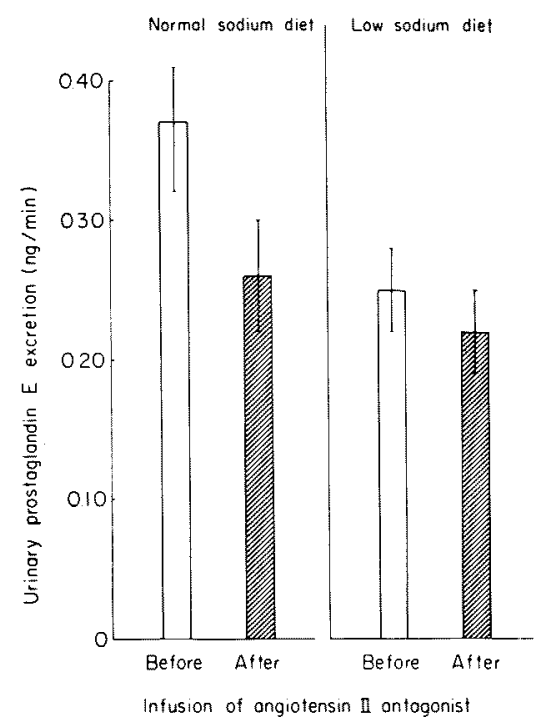

Fig. 1

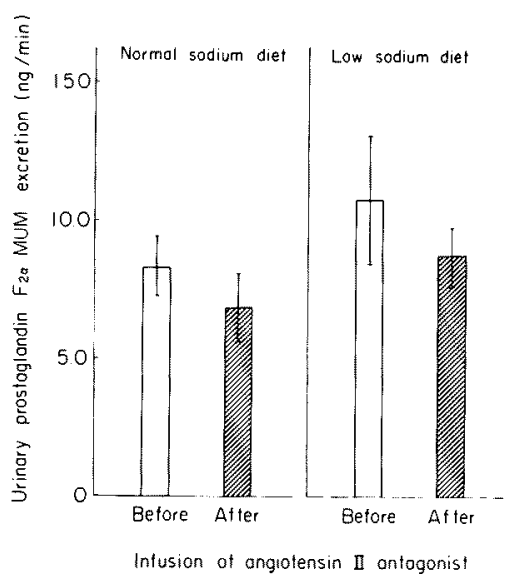

Fig. 2

Fig. 1. Effect of 1-Sar-8-lle-Angiotensin II on urinary PGE excretion in 18 patients with essential hypertension on normal and low sodium diets.

Fig. 2. Effect of 1-Sar-8-Ile-Angiotensin II on urinary PGF2aMUM excretion in 18 patients with essential hypertension on normal and low sodium diets.

It decreased from $8.3 \pm 1.0$ to $6.9 \pm 1.2 \mathrm{ng} / \mathrm{min}$, but the changes were not statistically significant. Similar effect was observed in 16 cases on low sodium diets; it decreased from $10.7 \pm 2.3$ to $8.7 \pm 1.0 \mathrm{ng} / \mathrm{min}$, again without any statistical significance (Fig. 2).

\section{Effect of 1-Sar-8-Ile-Angiotensin II on urinary aldosterone excretion}

Urinary aldosterone excretion before the administration of 1-Sar-8-IleAngiotensin II on normal and low sodium diets were $3.4 \pm 1.1$ and $7.7 \pm 2.1 \mathrm{ng} /$ min, respectively. After the infusion of the peptide, they decreased to $1.9 \pm 0.6$ and $6.0 \pm 2.7 \mathrm{ng} / \mathrm{min}$, respectively (not statistically significant) (Fig. 3). Decrease in urinary aldosterone excretion after the infusion of this peptide was found in 8 cases on normal sodium intake and in 11 cases on low sodium intake.

Effect of sodium depletion on urinary excretions of $P G E, P G F 2 \alpha M U M$, and aldosterone

Urinary sodium excretion on normal and low sodium diets were $160.8 \pm 13.3$ and $26.5 \pm 2.7 \mathrm{mEq} /$ day, respectively. Fig. 4 shows the changes of urinary excretions of PGE, PGF2aMUM and aldosterone following the restriction of sodium intake. Urinary PGE excretion decreased from $0.37 \pm 0.05$ to $0.25 \pm 0.03$ $\mathrm{ng} / \mathrm{min}(p<0.05)$. The excretions of $\mathrm{PGF} 2 \alpha \mathrm{MUM}$ and urinary aldosterone on normal sodium diet were $8.3 \pm 1.0$ and $3.4 \pm 1.1 \mathrm{ng} / \mathrm{min}$, respectively. After sodium 


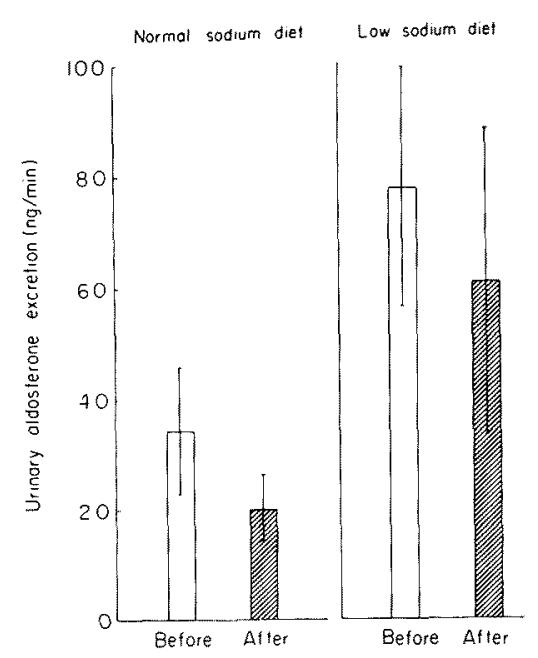

Fig. 3. Effect of 1-Sar-8-Ile-Angiotensin II on urinary aldosterone excretion in 14 patients with essential hypertension on normal and low sodium diets.
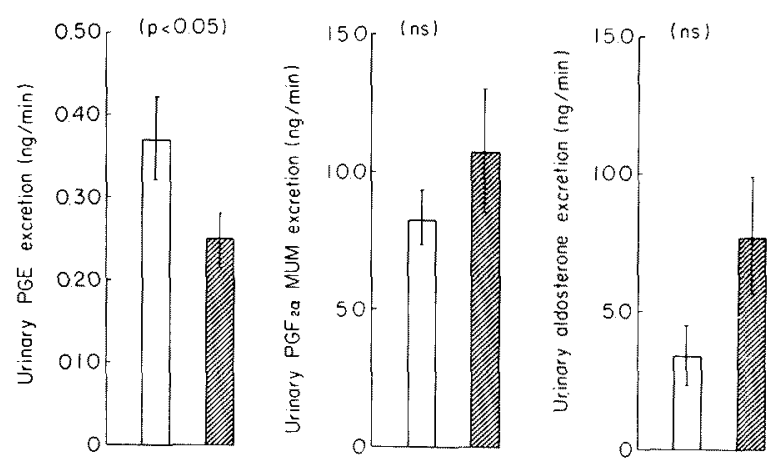

Fig. 4. Changes in the excretions of urinary PGE, PGF2aMUM and urinary aldosterone following the decrease of sodium intake.

$\square$, before sodium depletion;

depletion, PGF2aMUM excretion increased to $10.7 \pm 2.3 \mathrm{ng} / \mathrm{min}$ and urinary aldosterone excretion increased to $7.7 \pm 2.1 \mathrm{ng} / \mathrm{min}$, but these changes were not statistically significant.

\section{Relationship between plasma renin activity and urinary PGE excretion}

Fig. 5 shows the relationship between the level of plasma renin activity and the excretion of urinary PGE before the infusion of 1-Sar-8-Ile-Angiotensin II on normal sodium diet. There proved a positive correlation $(r=0.6977, p<0.01)$. On low sodium diet, however, no correlation was observed between them (data not shown). 


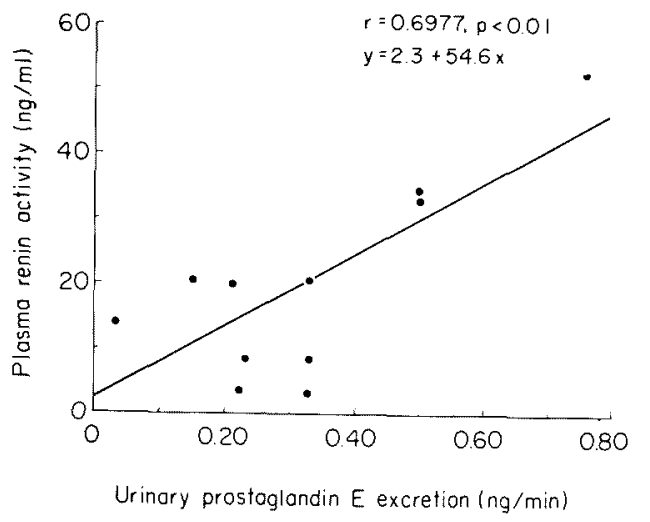

Fig. 5. Relationship between the level of plasma renin activity and the excretion of urinary PGE before the infusion in 13 patients with essential hypertension on normal sodium diet $(r=0.6977, p<0.01)$.

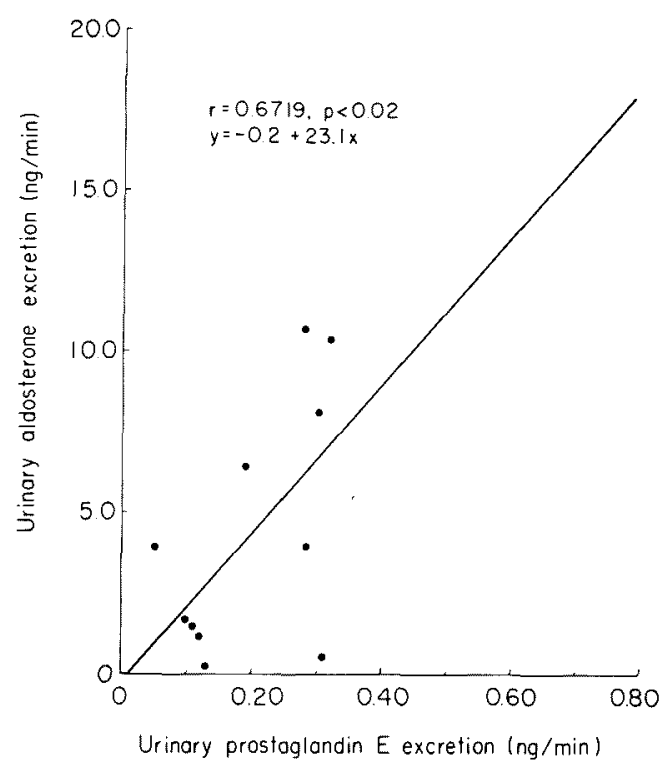

Fig. 6. Relationship between the excretion of urinary aldosterone and that of urinary PGE before the infusion in 14 patients with essential hypertension on low sodium diet $(r=0.6719, p<0.02)$.

Relationship between urinary aldosterone excretion and urinary $P G E$ excretion

A positive correlation was observed between the excretion of urinary aldosterone and that of urinary PGE on low sodium diet before the infusion of the peptide $(r=0.6719, p<0.02)$, as shown in Fig. 6 . On normal sodium diet, however, no correlation was observed between the two parameters. 


\section{Discussion}

The present study was undertaken to investigate the interaction of the renin angiotensin aldosterone system and the renal $P G$ in patients with essential hypertension. For this purpose, urinary PGE excretion as an indicator of renal $\mathrm{PG}, \mathrm{PGF} 2 \alpha \mathrm{MUM}$ excretion, urinary aldosterone excretion and plasma renin activity were measured before and after the infusion of 1-Sar-8-Ile-Angiotensin II to the patients on normal and low sodium diets.

Recently, some investigators reported that angiotensin II might stimulate the synthesis or release of renal PG (Vane and McGiff 1975; Satoh and Zimmerman 1975), and aldosterone might also influence them in animal experiment (Nasjletti and Colina-Chourio 1976). In man, it was reported by Lee et al. (1976) that plasma PGA, as well as plasma renin activity and urinary aldosterone excretion, increased after sodium depletion and that there were significant correlations between them. But there are many investigators who question the renal origin of plasma PGA (Strong et al. 1966; McGiff et al. 1974) and some of them are of the opinion that PGA is an artifact, not a naturally occurring $\mathrm{PG}$. We also consider that the plasma PGA is not an indicator of renal $P G$, because the level of plasma $P G$ was influenced by many factors, one of which is the generation of PGE in thrombocyte (Jubiz and Frailey 1974). Frölich et al. (1975) reported that urinary $P G$ may be of renal origin since urinary $P G$ was increased after the infusion of arachidonic acid, the precursor of $P G$, and also by the infusion of angiotensin II into the renal artery. Their opinion that urinary $\mathrm{PG}$ is a reflection of the synthesis or release of renal PG has been supported by Gill et al. (1976) and Papanicolau et al. (1976).

Our present study indicates that urinary PGE excretion decreases after the administration of the angiotensin II antagonist and it has a significant positive correlation with the level of plasma renin activity before the infusion of this peptide in patients on normal sodium diet. These results suggest that angiotensin II influences the synthesis or release of renal PG under this condition. On low sodium diet, however, the urinary PGE excretion did not increase in spite of an elevation of plasma renin activity and it did not decrease after the infusion of the peptide. Although this result differs from that of Lee's who used plasma PG as an indicator of renal $\mathrm{PG}$, it seems reasonable to assume that the excretion of urinary PGE decreases when the urinary excretion of sodium is low, because it has been well known that PGE has a potent natriuretic action. Papanicolau et al. (1976) reported that urinary PGE excretion increased after sodium repletion. After the sodium depletion, urinary PGE excretion showed a significant positive correlation with the excretion of urinary aldosterone, but it had no correlation with the levels of plasma renin activity. Accodingly, angiotensin II might not directly influence the synthesis or release of renal PG when sodium intake is low.

Little is known about the role of $\mathrm{PGF}$ in the regulation of blood pressure and sodium metabolism (Abe et al. 1976). PGF2aMUM excretion tended to increase after sodium depletion and to decrease after infusion of the angiotensin II antag- 
onist on either of normal and low sodium diets, but these changes were not statistically significant. The changes in PGF2aMUM excretion is not similar to those for urinary PGE. The reason for this difference is unknown.

It may be concluded that the synthesis or release of renal $P G$ might be influenced by angiotensin II in patients with essential hypertension on normal sodium diet, but not when they are on low sodium diet.

\section{Acknowledgments}

1-Sar-8-Ile-Angiotensin II was supplied by Daiichi Pharmaceutical Company, Osaka. This work was supported by research grants (No. 157229 and No. 110810) from the Ministry of Education, Science and Culture, Japan. The authors acknowledge the technical assistance of Miss Michiko Abe.

\section{References}

1) Abe, K., Otsuka, Y., Saito, T., Siang, C.B., Aoyagi, H., Miyazaki, S., Irokawa, N., Seino, M., Miura, Y., Ono, I., Minai, K., Kobayashi, K., Seki, T., Sato, T. \& Yoshinaga, K. (1972) Measurement of plasma renin activity by angiotensin I radioimmunoassay: a modification of Haber's method. Jap. Circulat. J., 36, 741-749.

2) Abe, K., Otsuka, Y., Yasujima, M., Chiba, S., Seino, M., Irokawa, N., Yoshinaga, K., Hirata, F., Ohki, S., Nakazawa, N. \& Hanyu, T. (1976) Metabolism of PG in man: effect of furosemide on the excretion of the main metabolite of PGF2a. Prostaglandins, 12, 843-848.

3) Frölich, J.C., Wilson, T.W., Sweetman, B.J., Smigel, M., Nies, A.S., Carr, K., Watson, J.T. \& Oates, J.A. (1975) Urinary prostaglandins. J. clin. Invest., 55, 763-770.

4) Gill, J.R., Frölich, J.C., Bowden, R.E., Taylor, A.A., Keiser, H.R., Seyberth, H.W., Oates, J.A. \& Bartter, F.C. (1976) Bartter's syndrome: a disorder characterized by high urinary prostaglandins and a dependence of hyperreninemia on prostaglandin synthesis. Amer. J. Med., 61, 43-51.

5) Jaffe, B.M., Behrman, H.R. \& Parker, L.W. (1973) Radioimmunoassay measurement of prostaglandin E, A, and $\mathrm{F}$ in human plasma. J. clin. Invest., 52, 398-405.

6) Jubiz, W. \& Frailey, J. (1974) Prostaglandin E generation during storage of plasma samples. Prostaglandins, 7, 339-344.

7) Langen, J., Jackson, R. \& Adlin, E.V. (1974) A simple radioimmunoassay for urinary aldosterone. J. clin. Endocr., 38, 189-193.

8) Lee J.B., Patak, R.V. \& Mookerjee, B.K. (1976) Renal prostaglandin and the regulation of blood pressure and sodium and water homeostasis. Amer.J. Med.. 60, 798-816.

9) McGiff, E.C. \& Vane, J.R. (1975) Prostaglandins and the regulation of blood pressure. Kid. Int., 8, 262-270.

10) MeGiff, J.C., Crowshow, K. \& Ikskovitz. (1974) Prostaglandins and renal function. Fed. Proc., 33, 39-47.

11) Nasjletti, A. \& Colina-Chourio, J. (1976) Interaction of mineralocorticoids, renal prostaglandins and the renal kallikrein-kinin system. Fed. Proc., 35, 189-193.

12) Ohki, S., Imaki, K., Hirata, F., Hanyu, T. \& Nakazawa, N. (1975) Radioimmunoassay of main urinary metabolite of prostaglandin F2a. Prostaglandins, 10, 549-555.

13) Papanicolau, N., Lefkos, N., Safar, M., Bairiety, J. \& Milliez, M. (1976) Direct relationship between urinary prostaglandin $\mathbf{E}$ and sodium excretion in essential hypertensive patients. Experientia, 32, 1280-1281.

14) Satoh, S. \& Zimmerman, B.G. (1975) Influence of the renin-angiotensin system on the effect of prostaglandin synthesis inhibitors in the renal vasculature. Circulat. Res., Suppl. to 36 and 37, I-89-I-96.

15) Strong, C.G., Boucher, R., Nowaczynski, W. \& Genest, J. (1966) Renal depressor lipid. Mayo Clin. Proc., 41, 433-452. 
16) Vane, J.R. \& McGiff, J.C. (1975) Possible contributions of endogenous prostaglandins to the control of blood pressure. Circulat. Res., Suppl. to 36 and 37, I-68-I-75.

17) Zusman, R.M. (1972) Quantitative conversion of PGA or PGE to PGB. Prostaglandins, 1, 167-168. 